\title{
Controvèrsia inquisitorial al segle XVIII entorn de la pintura d'una beata estigmatitzada
}

\section{Inquisitorial confrontation in the eigteenth century about the Painting of a blessed stigmatized}

\author{
Alfonso Esponera Cerdán op. \\ aespo.ar@dominicos.org \\ Maria-Pilar Sastre Alzamora \\ pilar@sastrealzamora.com \\ Facultat de Teologia de València \\ Universitat de les Illes Balears
}

Resum: L'any 1738, un frare del convent de Sant Domingo de Palma havia de defensar unes «Conclusions literàries» teològiques, dedicades a la beata dominica Llúcia de Narni. El full de propaganda de l'acte que s'havia repartit duia impresa una làmina de la beata, amb les llagues dels estigmes a les mans i al costat. El tribunal de la inquisició, arran d'una denúncia dels franciscans observants, va manar que se suspengués aquest acte acadèmic. Els dominics apel laren a Madrid i a Roma. Aquest és un exemple més de com les dones -a més d'altres estigmatitzats- foren víctimes de l'actitud monopolista dels franciscans, així com una expressió dels enfrontaments crònics entre els ordes mendicants mallorquins.

Paraules clau: Estigmatitzats, Dominics, Franciscans, Mallorca

\begin{abstract}
In 1738, in the church of the convent at Santo Domingo at Palma, a friar offers some theological 'literal conclusions' which he dedicates to the Blessed dominican Lucía de Narni. The Propaganda Act is written on a sheet, and having been distributed, mentions the stigmata on the hands and side of the blessed. The Inquisition, influenced by the Franciscans, denounces and orders the suspension of the designated academic ceremony. The Dominicans appeal to Madrid and Rome. This is another example of women, along with other stigmatized, that were victims of the monopolistic attitude of the Franciscans. It is also an expression of the chronic confrontations between the two mendicants orders in Mallorca.
\end{abstract}

Keywords: Stigmatized, Dominican, Franciscan, Mallorca

\footnotetext{
* Aquest article s'insereix en el marc dels següents projectes R+D+I: «La catedral ilustrada. Iglesia, sociedad y cultura en la Valencia del siglo XVIII» HAR2012-32893 (MINECO); «Estrategias documentales aplicadas a los procesos de restauración y divulgación del patrimonio artístico religioso de Mallorca». HAR2015-66307-P (MINECO/FEDER).
} 
Alfonso Esponera Cerdán \& Maria-Pilar Sastre Alzamora. Controvèrsia inquisitorial al segle XVIII entorn de la pintura d'una beata estigmatitzada

Els dies 13 i 14 de juny del 1738, un frare del convent de Sant Domingo de Palma havia de defensar unes «Conclusions literàries» teològiques, dedicades a la beata dominica Llúcia de Narni. El full de propaganda de l'acte que s'havia repartit duia impresa una làmina de la beata, amb les llagues dels estigmes a les mans i al costat. El tribunal de la inquisició de Mallorca, arran d'una denúncia dels franciscans observants, va manar el dia 13 que se suspengués aquest acte acadèmic, que com tots els d'aquest tipus hauria estat tot un esdeveniment social, i així es va fer.

D'altra banda, a un altar de la capella dels Reis Mags d'aquella església conventual, hi havia una representació de la beata estigmatitzada, davant la qual es va encendre una espelma els dies 17, 18 i 19 posteriors; al claustre hi havia una altra representació de la beata. Els franciscans també ho denunciaren al Sant Tribunal de la Inquisició, que es va pronunciar sobre aquest afer.

Els dominics apel laren a la Inquisició General de Madrid. Els franciscans acudiren al bisbe perquè suspengués unes noves Conclusions a la mateixa església, qui els va fer cas. Finalment, els dominics elevaren aquesta causa a la Sagrada Congregació de Ritus, la qual també s'hi va pronunciar.

Tots aquests fets varen generar una important controvèrsia segons la documentació inèdita que se'n va produir i que és la que es presenta en aquest treball. Però abans de continuar, convindria tenir en compte alguns aspectes.

\section{1.- Consideracions generals}

Entre el 1753 i el 1756, el dominic Tomàs Febrer va escriure una voluminosa Historia de las grandezas del Real Convento de Santo Domingo, Orden de Predicadores, de Palma de Mallorca, en la qual afirma que a partir del 1708 i fins al 1750 hi va haver pau i harmonia entre els dominics, el capítol catedral i els jurats de la ciutat en els assumptes relacionats amb Ramon Llull, ${ }^{1}$ afirmació que no és del tot exacta, almenys entorn del 1712 (Pérez Martínez 1986: 63-77), ja que no podem oblidar els enfrontaments més o menys declarats amb els franciscans i els jesuïtes, principalment.

També cal assenyalar les gestions que, per iniciativa dels Protectors de la Causa Pia Lul liana, a partir de la fi del 1746 (Pérez Martínez 1966: 194-197) es dugueren a terme per a la confirmació per part de la Santa Seu del culte immemorial que es donava a Llull a Mallorca i que donaren peu al que es coneix com Segundo Proceso diocesano para probar el culto inmemorial. Va ser en aquests moments que es va començar a divulgar en còpies manuscrites una petita obra anònima antilul liana -del dominic Sebastià Rubí?- que duia per títol Aliquae observationes super cultu qui Raymundo Lullo in Majorica exbibetur

1 Breve resumen .... f. 237. 
Alfonso Esponera Cerdán \& Maria-Pilar Sastre Alzamora. Controvèrsia inquisitorial al segle XVIII entorn de la pintura d'una beata estigmatitzada

(Pérez Martínez 1966: 198-199). ${ }^{2}$ La Sentencia definitiva la va donar finalment, amb data d'1 d'octubre del 1749, el bisbe de la diòcesi José Antonio de Cepeda.

D'altra banda, els dominics estaven celebrant i potenciant la figura de la beata Llúcia de Narni (14761544). Aquesta dominica italiana, durant la nit del 24 al 25 de febrer del 1496, va viure un èxtasi profund mentre estava recollida en oració al cor conventual juntament amb les altres germanes. Crist li va imprimir misteriosament les llagues sagrades, que posteriorment varen confirmar com a autèntiques les autoritats pertinents. ${ }^{3} \mathrm{El}$ seu culte havia estat confirmat per Climent XI l'1 de març del 1710 i així, un any després, es va imprimir a la ciutat de Palma una traducció a l'espanyol de la Vida de Santa Catalina de Siena, amb el parer del dominic Vicente Justiniano Antist, amb una addició a la vida d'aquesta beata. A més, Benet XIII va estendre el seu res a tot l'orde el 5 de febrer del 1729. ${ }^{4}$ Un any més tard, es va imprimir en espanyol, de nou a Palma, un Libro de la Tercera Orden de Santo Domingo, compost pel doctor Calafat, que també tractava de l'esmentada beata. A tot això cal afegir les prèdiques públiques durant la seva festa anual, com també la impressió de nombroses làmines de la beata estigmatitzada. El 1735, fins i tot s'imprimiren i defensaren a la Universitat unes Conclusions dedicades a la beata, en l'anunci de les quals hi havia una làmina on apareixia pintada amb llagues «y a ellas concurrieron con otra mucha gente de todas clases, los religiosos Franciscos». ${ }^{5}$

Els pronunciaments pontificis i les dates respectives del 1710 i del 1729 s'han de tenir molt en compte en tot aquest assumpte. ${ }^{6}$

A més, segons la tradició dominicana, hi va haver altres dones estigmatitzades, a les quals es fa referència en la documentació que es presenta, com ara santa Caterina de Ricci (1522-1590) (Benavente Eyriey 2008: 209-218) i santa Caterina de Siena (1347-1380) (Benavente Eyriey 2008: 296-301); a aquesta santa, Déu li va regalar gràcies místiques amb molta freqüència, com ara els estigmes del 1375. Però el 1472, el papa Sixt IV, a petició del ministre general i del capítol dels franciscans celebrat a Ferrara, defensors de l'autèntica estigmatització de sant Francesc d'Assis, va emetre una butlla segons la qual els dominics s'havien d'abstenir de parlar de la prerrogativa celestial

2 L’autor conclou que li sembla difícil que de la permissió del culte -que la Santa Seu consent a Mallorca- se’n pugui deduir l'aprovació i, molt menys, la beatificació. Els dominics de la ciutat eren pregonament antilul lians, la qual cosa generava seriosos enfrontaments (Esponera Cerdán 2004: 245-274).

3 Vegeu Granello (1879), Brugnola (1989), Benavente Eyriey (2008: 200-207) i Montero (2016). Actualment, la seva memòria és celebrada per l'orde de predicadors el 14 de novembre.

4 Així es denunciarà a les Actes del Capítol General celebrat el 1748, a Reichert (1904: 106-107).

5 Per a totes aquestes notícies de Palma respecte a l'afer: Discurso juridico ...f. 112v; i afegeix: «pero ni ellos ni otro alguno ha hablado palabra hasta aora, sin embargo de no ignorar todo lo que se ha expressado, pues es tan notorio que no cabe ignorancia de ello».

6 Autos sobre ...ff.112v-113a.

SCRIPTA, Revista internacional de literatura i cultura medieval i moderna, núm. 8 / desembre 2016 / pp. 301-313 ISSN: 2340-4841 · doi:10.7203/SCRIPTA.8.9301 
-que es creia atorgada a la santa de Siena- de portar impreses en el cos les llagues de Jesucrist, que en un termini d'un any s'havien de retirar les seves figures en què aparegués amb els estigmes i que, en el futur, no se'n fessin imatges que exhibissin aquest privilegi diví, fins que el pontífex romà no resolgués altrament. El 1630, Urbà VIII va reconèixer els estigmes caterinians i, deu anys després, Bounisegni va escriure Il trionfo delle stigmate di Santa Caterina da Siena.

\section{2.- Intervenció del tribunal de la inquisició de Mallorca}

Com ja s'ha esmentat, el 13 i 14 de juny del 1738 fra Lluís Esterlich, frare del convent de sant Domingo de Palma, havia de defensar a l'església conventual unes "Conclusions literàries», teològiques, dedicades a la beata Llúcia de Narni. El full de propaganda de l'acte que s'havia repartit duia impresa una làmina de la beata dominica, amb les llagues dels estigmes a les mans i al costat. Davant això, els franciscans observants presentaren una denúncia al tribunal de la inquisició de Mallorca.

Pot cridar l'atenció que aquest assumpte es portés a aquest tipus de tribunal, car no hi havia una heretgia expressa ni era una representació que pogués atemptar contra la moral, però cal no oblidar que es considerava una desviació heterodoxa no acatar els pronunciaments pontificis, dels quals n'hi havia hagut des del segle XV.

A l'Arxiu Històric Nacional (Madrid) -Inquisición Legajo $4461 n^{\circ} 8$ y 9- hi ha un manuscrit que és una còpia administrativa que conté tot allò que havia dictaminat el tribunal. El títol -que es referix a dues actuacions successives- és el següent: Autos sobre haver sacado a luz una lamina de la Beata Lucia de Narni con llagas los PP. Dominicos, con dedicatoria a ella, en unas Conclusiones; y haver encendido una vela delante de otra, que está en la Capilla de los Reyes, después de haverseles mandado suspender las Conclusiones (f. 2). ${ }^{7}$

Pel que fa a la primera, informa que l'11 de juny, «estando en los quartos de su havitación por la mañana por ser día feriado [de l'Octava del Corpus] el Señor Inquisidor Lizenciado Don Joseph de Luzurriaga, ${ }^{8}$ vino a ellos a su voluntad un religioso de San Francisco de Assís, el qual siendo presente fue recivido juramento...» (f.3). Aquest franciscà era fra Antoni Oliver, lector de filosofia al convent de la ciutat, de 28 anys d'edat.

Doncs bé, en aquesta audiència va denunciar les Conclusions que havia de defensar els dies 13 i 14 de juny següents el dominc fra Lluís Estelrich al convent de Sant Domingo, «[que] están dedicadas a la Beata Lucía de Narni, cuya figura se halla a la frente de ellas con señales de llagas en las manos

\footnotetext{
7 Mentre no s'indiqui altrament, en aquest document s'accentuaran les paraules per facilitar-ne la comprensió; però per evitar les nombroses notes al peu, s'assenyalarà en el text el foli corresponent. Les actes del capítol provincial del 1742 no es fan ressò d'aquest assumpte (Acta Capituli Provincialis... 1742. Caesar-Augustae 1742, conservades a AHPDA n. 23).

8 «En ausencia de esta ciudad del Señor Inquisidor don Antonio Pelegrin» (f. 5).
} 
y costado, lo qual es contra las Bullas que expressa el Memorial que presenta en nombre de su Provincia de Mallorca» (ff. 3-4). ${ }^{9}$ A més, a la dedicatòria s'afirmava «haverlas recivido de Cristo Señor» (f. 34) aquestes llagues.

El dia 12 següent, l'inquisidor Luzuriaga, i en el mateix indret, va convocar dos qualificadors: els pares jesuïtes Juan Antonio Ferrando i Joseph Ramonell. Els va mostrar la delació i els va preguntar quina providència hauria de prendre el tribunal.

«Dixeron conformes que debía mandar suspender las dichas Conclusiones por hallarse prohibido por Sixto IV [en sengles butlles del 1472 i del $1475^{10}$, aplicades a santa Catarina de Siena] que Santo alguno, o Santa, Beato o Beata se pinte o figure con llagas ${ }^{11}$, mientras no halla declaración de la Silla Apostólica de haverlas tenido el Santo o Santa que se guarde pintar con ellas, exceptuando las imágenes de San Francisco de Assis ${ }^{12}$, y que luego se les intimasse a los religiosos Dominicos la dicha orden de suspender las Conclusiones, para que -si tubiessen título o razón para pintar con llagas a la dicha Beata Lucía- la pudiessen alegar y en su vista se procediesse con acierto, revocando la dicha orden o manteniéndola; y lo firmaron» (ff. 5-6).

El secretari ho va comunicar immediatament al convent en la persona de fra Jacint Pujadas, prior (el document l'anomena «president») del convent, i a fra Lluís Estelrich. Els dominics respongueren que s'entrevistarien amb l'inquisidor. "Como con efecto lo hicieron muy poco tiempo después de haver dado yo [el Secretario] parte a dicho Señor Inquisidor de haver executado su orden» (f. 7). En aquella entrevista aquell mateix capvespre, el pare mestre Jacint Pujadas, davant aquesta suspensió de la defensa, va indicar a l'inquisidor que defensarien les Conclusions amb una altra dedicatòria a santa Teresa ${ }^{13}$ (f. 9). Però l'acte de defensa de les Conclusions es va suspendre.

El dia 13, el secretari va comunicar als dos qualificadors esmentats que els dominics -a través del pare Pujadas- havien al legat que «las bullas de Sixto IV del segundo y quinto año de su pontificado

9 Aquest memorial comença: «Haviendo salido a luz pública ciertas Conclusiones»; i acaba: «por oponerse a determinaciones expresas de la Silla Apostólica»; i es transcriu (ff. 4-5). També s’assenyala que a continuació hi ha les Conclusions (f.5), s'entén que es refereix al full imprès de propaganda de l'acte, però aquest no hi figura.

10 Transcripció de la butlla en llatí, conservada aleshores a l'Arxiu Diocesà de Mallorca, tot informant l'autor: «Lib. Colacions de 1480-83, sen foliar, aprés d'una presentació de benefici de 29 maig de 1483», a Sanxo, P.A. (1930-1931), p. 436.

$11 \mathrm{El}$ text pontifici indicava, a més, que «nec aliquis in predicationibus ad populum».

12 Francesc d'Assis va ser canonitzat el 1228, però sembla ser que al cap de poc temps ja hi va haver problemes per pintar-lo estigmatitzat. I així «la Religión [dels franciscans] empeçó a pintarlo como era razón con aquellas divinas señales. Y como algunos indevotos del Patriarcha lo contradixessen, Gregorio nono [1227-1241] y Alexandro cuarto [1254-1261] con toda tiesura y valor lo defendieron diziendo, en sus Bulas respective, que pues San Francisco tuvo en vida impresas aquellas señales, era muy conforme a la razón y a la justicia que se pintasse con ellas» (Autos, ff. 23-24). La festa de la impressió de les seves llagues se celebrava litúrgicament el 17 de setembre.

13 Amb gairebé tota seguretat es refereix a santa Teresa d'Àvila -i a la seva transverberació?

SCRIPTA, Revista internacional de literatura i cultura medieval i moderna, núm. 8 / desembre 2016 / pp. 301-313 ISSN: 2340-4841 · doi:10.7203/SCRIPTA.8.9301 
en que prohivió pintar con llagas a Santa Catharina de Sena ni otra de quien la Silla Apostólica no hubiesse declarado haverlas tenido no fueron admitidas; y que quando [en comptes de «aunque»] lo hubieran sido, Alexandro VI expidió otra diez años después en que mandó expresamente que se pintasse dicha Santa Catharina con llagas y que Clemente octabo ordenó lo mismo por un decreto, mandando que no obstante las Bullas de Sixto IV en contrario, nadie se atreba contradezir ni alterar sobre este punto; y que para prueba de lo expressado havían exivido la Vida de Santa Cathalina escrita por el Padre fray Lorenzo Gisbert dominico, impressa en Valencia en el año de 1690. Assimismo el Oficio [Divino] que se reza de dicha Santa Cathalina en la universal Iglessia y una concessión de Benedicto XIII manuscrita a dichos religiosos dominicos de que pudiesen celebrar todos los años la memoria de la impressión de las llagas de dicha Santa Cathalina. Que en orden a la Beata Lucía havían mostrado su Vida impressa en Roma con licencia de los Superiores en el año de 1711, en la qual se halla al principio una lámina con señales de llagas en manos y costado. [El] Autor de la $V i d a$, [era] un religioso dominico. Y que dichos religiosos dominicos pretendían que por lo mesmo estaba permitido y tolerado pintar a dicha Beata Lucía con las llagas, y por esso se les debía, o podía conceder tubiessen las Conclusiones; y que esto no quitaba el que después se siguiesse la Causa» (ff. 7-9). Afegien que no acceptaven l'alternativa de canviar la dedicatòria per una altra i que «si no se les permitía la defensa de las Conclusiones dedicadas a la Beata Lucía, ningunas tendrían porque el actuante no quería defender otras que las dedicadas a la Beata Lucía; pero que si se mantenía la orden de que no se defendiessen estas y se les permitiesse la defensa de otras, que decían tenerlas también impressas, abrazarían acasso este medio y con esso se complacía a ambas partes: a la declarante y a los dominicos» (ff. 9-10). Possiblement es referien a les que pensaven defensar els dies 16 i 17 de juny següents, dedicades al noble Nicolau Veri (f. 63).

Els dos qualificadors esmentats respongueren mitjançant un escrit signat «que lo alegado hablaba de Santa Cathalina de Sena y prescindiendo si era verdad o no, no alegaban motivo alguno relebante digno de atención en defensa de las llagas de la Beata Lucía; y que su dictamen era el que se no se revocasse la orden de suspender dichas Conclusiones, y [que] se les podía permitir defenderlas con otra Dedicatoria» (f. 10).

Però la cosa no va acabar aquí. Els franciscans, pocs dies després, «[habían] advertido que en la Iglesia del Convento de Santo Domingo de esta capital de Mallorca en un altar público [«en la Capilla de los Reyes Magos», "vecina a la Sachristía a la entrada del Claustro»] ${ }^{14}$ y [en el] Claustro [estaba] la figura de dicha Beata con las mesmas llagas» ${ }^{15}$ (f. 34), i que es va encendre una espelma davant la imatge de la capella els dies 16, 17 i 18, en la funció prèvia a les esmentades Conclusions

14 «En dicha Capilla se descubre en dos partes con llagas bien patentes en manos y costado y en una de las dos a la pressencia de Christo Señor como indicándole author de dichas llagas» (f. 51; cf. ff. 42.50).

15 «La figura de la Beata Lucia de Narni con la esclarecida prerrogativa de llagas patentes en manos y costado y la expressión de haverlas recevido de Cristo Señor» (f. 42). 
dedicades al noble Nicolau Veri. ${ }^{16}$ S'afirmava que «de esto último tuvieron los Religiosos Franciscos la primera noticia día 16 de junio del corriente año 1738» (f. 40), la qual cosa estranya una mica, car el culte públic a la beata s'havia confirmat dècades abans i, per tant, és molt possible que a partir del moment que se'n va rebre notícia a Palma es representàs així la beata.

En el conjunt documental utilitzat, es transcriuen a continuació dos escrits en els quals justifiquen la seva postura tant els dominics (ff. 11-32) com els franciscans (ff. 34-47), totes dues justificacions força tedioses i molt de l'època.

La dels frares predicadors, d'autor desconegut, assenyala que en aquest assumpte s'han de fer dues «inspeccions», o determinacions, expressió de la pregona mentalitat escolàstica que encara imperava: «La primera si es prudencialmente crehíble que dicha Beata Lucia viviendo las tuvo en su cuerpo impressas por Cristo Señor Nuestro. La segunda en casso afirmativo, si se puede pintar o imprimir con dichas llagas sin contravenir a las Constituciones, o Bulas Pontificias» (f. 11).

Aborda amb diversos i nombrosos arguments les dues qüestions, tot insistint en el quid juris de l'assumpte, i hi analitza diversos aspectes de forma i contingut de les dues butlles de Sixt IV, la del 1472 i la del 1475, tot assenyalant, per exemple, irregularitats, o defectes, de forma, atès que és probable que no fossin despatxades per via ordinària, alhora que es formulaven dubtes sobre la seva autenticitat. També s'estudien les seves afirmacions en relació amb l'estigmatització de santa Caterina de Siena (ff. 19-28). ${ }^{17}$ I arriba a aquesta conclusió: «Es constante y cierto (certitudine factio) que después de las dos susodichas Bullas de Sixto 4 han escrito graves doctos y píos authores exponiendo sus libros impressos a la publicidad del mundo, sobre las llagas de diferentes Santos, o Santas, Beatos o Beatas, sin que nadie se haya mostrado hasta ahora tan zeloso de la observancia de las dichas dos Bullas, o también sin que ninguno de los susodichos authores aya tenido el menor escrúpulo dello» (f. 28; cf. ff. 28-30). Les mencions a dones només apareixen quan es parla en general de santes o beates.

Per la seva banda, a l'escrit dels frares menors, també d'autor desconegut, contesten a cadascun dels arguments donats pels dominics en el seu escrit antecedent, la qual cosa fa pensar que ja el coneixien.

16 Aquestes Conclusions també generaren una segona intervenció del tribunal inquisitorial mallorquí (ff. 61-75), originada el 17 de juny del 1738 per l'acusació de Joseph Reus, doctor en filosofia, acòlit beneficiat de la catedral, que, a més, era alumne de l'escola dels jesuïtes (!), sobre dos petits paràgrafs de l'oda de l'anunci que hi apareixien impresos (són al f. 121), que havia de defensar Jacobus Puigserver i Company, batxiller en filosofia, dedicades al noble Nicolau Veri, que podrien contenir una heretgia eucarística. Es transcriuen els breus pronunciaments dels qualificadors i el fiscal, i acaba amb la sentència absolutòria (f. 75).

17 S'addueix l'obra del dominic Vicente Justiniano Antist Pro Divae Catharinae Senensis imaginibus dilucida, brevisque disputatio, impresa en castellà a València el 1583 i, posteriorment, se'n van publicar diverses edicions en llatí al llarg dels anys. Això és senyal que el tema preocupava, i es descriu com un «debate tan ruidoso, que entonces havía entre las dos Religiones Franciscana y de Predicadores» (Autos sobre...,f. 24), i que en el cas de santa Caterina només resoldrà el 1630. A Mallorca, la devoció cap a aquesta santa va augmentar al segle XVII, concretament entorn del 1659 a càrrec de Joan Baptista Despuig i Sant Martí. [Campaner (1881: 420; Breve resumen .... fol.. 149]. 
Aquí es formulen per primera vegada i clarament el principi i el postulat que fonamenten i sostenen la seva postura: que no "puede afirmarse que otro, u otra, distintos de San Francisco de Assís hayga tenido el Privilegio de llagado de Cristo Señor asta que lo determine y dé licencia especial la Santa Sede Apostólica» (f. 34). «Porque los Santos de Dios deven ser honrados con prerrogativas y gracias verdaderas, y ciertas; ¿y quién duda que puede celebrarse por una de las más tamañas haver recivido un Siervo de Dios las insignias de nuestra Redempción del mesmo Redemptor de nuestras almas?» (f. 38). S'hi afegeix «que la summa reverencia devida a Christo Señor pide no se hagan sus llagas con franquesa comunes, que por esso dize el Pontífice se requiere evidencia, y certitud del hecho $[\ldots]$ y tal evidencia y certitud debe venir a los fieles de la misma Sede Apostólica, como dize el mesmo Sixto [...; eliminant, a més, d'aquesta manera] ocasiones de escándalos en los cultos de los Santos con prerrogativas singulares, que sin duda no siendo aprobadas por la Iglesia ni menos ciertas, se exponen a la nota de supersticiosos» (ff. 38-39). No hi apareix cap altra menció a dones més que quan es parla en general de santes o beates.

D’altra banda, assenyala que Sixt VI, en la seva butlla, «[en tiempos] de llagas y llagados, para impedirlo del todo, prohibe baxo pena de excomunión mayor late sententiae, reservada a la Santa Sede, predicar y de qualquier otro modo afirmar que Santo, o Santa, Beato o Beata, exceptuando San Francisco, haya tenido el privilegio de dichas llagas» (f. 35). Més endavant afegeix que el papa, en aquesta butlla, "[sotmet] las Iglesias en que se hallassen figuras de Santa Cathalina o de otro Santo, o Santa, Beato o Beata, con dichas llagas a la censura de entredicho eclesiástico, y obligando a los que se mantuviessen inobedientes por seis meses, que fuessen compelidos a responder delante de los Obispos e Inquisidores contra la herética pravedad, como sospechosos del crimen de heregía para destruir la costumbre introducida de pintar figuras con llagas, predicar y de qualquier manera afirmar que Santo, Santa, Beato o Beata, exceptuando a San Francisco» (f. 41). Semblaria ser que, a la butlla del 1475, es matisa i dulcifica tot això, tot i que els franciscans no ho indiquen, almenys pel que fa a la santa de Siena. Per tant, segons ells, els predicadors, amb la seva desobediència, «incurren en la excomunión mayor, y más penas fulminadas de Sixto» (f. 36).

També s'esmenta el Concili de Trento, que en la seva sessió del 3 de desembre del 1563 va determinar «no ser lícito a alguno el poner en algún lugar o Iglesia, aunque de cualquier modo exceptuada, o mandar que se ponga imagen sin aprobación del Obispo, y assí mesmo manda no se admitan nuevos prodigios inconsulto [el] Santissimo Romano Pontífice» (f. 40).

El matí del 21 de juny es torna a presentar Antoni Oliver tot sol davant l'inquisidor Luzuriaga (ff. 48-50), car Antonio Pelegrin, l'altre inquisidor, continuava absent, per denunciar en nom dels franciscans i presentar un memorial sobre el fet que s'hagués encès una espelma davant la imatge de la beata Llúcia de Nari els dies 16, 17 i 18, en la funció prèvia a les Conclusions, la qual cosa no s'havia fet fins aleshores.

En aquest memorial (ff. 50-52) es relaten els fets, que testificarien diversos assistents, i se sol licita que s'ordeni esborrar les llagues i, en cas de no acatar aquesta ordre, que s'apliquin els càstigs assenyalats als infractors. 
Cinc dies després, Luzirraga i Pelegrin estudien el memorial i determinen que es reculli informació i l'opinió dels qualificadors (ff. 51-52). Aquests darrers són convocats per al dia 28 de juny a les vuit i mitja del matí (un trinitari calçat, dos jesuïtes, un agustí, un carmelita calçat, un mercedari i un mínim, ff. 53-54) i en aquesta reunió els set qualificadors conclouen que «avía sido escandaloso, irrisorio y despreciativo de lo mandado por el Tribunal; y [pero] tratando de la satisfacción que debía tomarse, discordaron algo» (ff. 54-57). Per la seva banda, Luzuriaga declara que «era conocido que se avía hecho para pública ostentación de las llagas y de este modo en contravención y desprecio de lo dispuesto por el Santo Oficio» (f. 79).

A continuació es transcriu un escrit, sense data, d'Antonio Pelegrin que consulta sobre la idoneïtat de tot el procés (ff. 78-89), adreçat molt probablement a altes instàncies de la inquisició. Apel laren els dominics a aquesta instància? ${ }^{18}$ I el dia 3 de setembre següent, el Consell General de la Inquisició a Madrid va manar que se suspengués aquesta sentència, ja que el tribunal de Mallorca no hauria d'haver prohibit les Conclusions, «porque esto no toca a el Santo Oficio, solo sí el proceder contra los que dan culto a los que no están canonizados, o beatificados según el Brebe de Urbano 8 de 13 de marzo de 1625 [...] por no haber jurisdicción el Santo Oficio para ello» (ff. 59-60).

Segons el cronista dominicà Febrer «con esta noticia passó el dependiente a combidar o avisar para defenderlas; lo qual sabido por los dichos Padres Franciscos, acudieron al Obispo de esta Diócesis para que suspendiesse dichas Conclusiones [futuras y en dicha Iglesia], y lo lograron». ${ }^{19}$ Però la intervenció d'aquesta autoritat -el benedictí Benet Panyelles i Escardó, qui havia assumit el seu càrrec el $1730 \mathrm{i}$ el mantindria durant tretze anys- amb prou feines s'esmenta en la documentació utilitzada. $^{20}$

Finalment, i segons el mateix Febrer, ${ }^{21}$ els dominics recorregueren a la Sagrada Congregació de Ritus a Roma.

18 Segons Febrer «acudió este Real Convento [de Predicadores de Mallorca] a la Inquisición General de Madrid; y resolvió esta que no tocava al dicho Tribunal decidir esta Causa, que era lo que pretendía este Convento". Breve Resumen... f. 210.

19 Breve Resumen... f. 210.

20 Massot i Muntaner, J. (1961), pp. 204-205 nota 24, parla d'un enfrontament força habitual d'aquest prelat amb el tribunal en assenyalar que un edicte seu del 1753 anava contra certes disposicions sinodals mallorquines en matèria de confessions, que autoritzava les confessions in domibus privatis, no només d'homes, sinó també de senyores -i únicament de senyores-, amb reixa o sense. El bisbe va enviar el seu escrivà major i secretari als senyors inquisidors perquè els demanés si hi havia alguna disposició nova quant a la jurisdicció de la inquisició en aquesta matèria i els advertís que, si no n'hi havia cap, exigia que es complissin estrictament les constitucions del sínode.

21 Breve Resumen... f. 210. 
Alfonso Esponera Cerdán \& Maria-Pilar Sastre Alzamora. Controvèrsia inquisitorial al segle XVIII entorn de la pintura d'una beata estigmatitzada

\section{3.- Evolució posterior de l'afer}

Sembla que qui va portar la causa va ser el pare mestre Josep Salas, ${ }^{22}$ i és gairebé del tot probable que un dels documents que va presentar és el que es conserva a l'Arxiu General de l'Orde de Predicadors a Roma -amb la sigla AGOP. Sèrie XIII. 21.100 (Epistulae variaque documenta, 15711777)-, ${ }^{23}$ si bé no duu data ni signatura.

Es titula: «Discurso jurídico sobre la suspención de Conclusiones que hizo el Señor Obispo en el Convento de Santo Domingo de la ciudad de Palma por estar pintada en ellas la Beata Lucía de Narni con llagas, y referirse que las tuvo en la dedicatoria».

Molt de l'època, també és de lectura força tediosa. S'hi ofereixen argumentacions jurídiques escolàstiques, molt detalllades i amb notes al marge, tot justificant «que los dominicos han podido justamente pintar y publicar con llagas a la Beata Lucía y que se hallan en esta possesión antiquíssima, quieta y justificada con los decretos Apostólicos, facultad de los Superiores y Ordinarios y con la autoridad y crédito de innumerables escritores píos y doctos» (p. 118a). Per tal d'argumentarho, d'una banda s'analitza el pronunciament de Climent XI del 1710, que en confirma el culte; i l'extensió del seu res a tot l'orde per Benet XIII del 1729 (pp.112v-113a). Però, a més, analitza les butlles de Sixt IV del 1472 i del 1475, tot aturant-se molt extensament en arguments molts semblants als que havien esgrimit els dominics de Palma en la primera intervenció, tot i que també els amplia.

D'altra banda, pel que fa a la finalitat i la causa que va motivar el papa Sixt IV -que en part era el fonament ja esmentat de la postura dels franciscans- només assenyala: «que no era justo que se pintasse con llagas a quien no las havía tenido y porque su Santidad no dava crédito [no tenia informació fidedigna encara] a que Santa Catharina de Siena ni otro que San Francisco las huviesse tenido, por esso expidió las dos Bullas» (p. 117a). Tanmateix, hi emfasitza el cas posterior de santa Caterina de Siena (pp. 113a-118a).

Conclou que se'ls retiri el greuge i addueix més raons concretes que justifiquen aquesta decisió i mesura (pp. 118r-121r).

22 Aquest religiós havia pres l'hàbit el 15 de setembre del 1681 al convent de la Mare de Déu del Rosari de Pollença a l'edat de 16 anys i va professar afiliat al convent de Sant Domingo de Palma l'any següent. Dedicat als estudis, va exercir com a lector en filosofia i després en teologia i va ser catedràtic de prima a la Universitat de Palma. Va ser elegit prior del convent de Palma el 1707, i reelegit el 1711; va construir «el nuevo dormitorio y celdas que se ven sobre el Claustro Mayor». Va tornar a ser prior a partir del 1720. Va tenir un gran prestigi i era molt estimat a la ciutat i va ser, a més, visitador dels convents de l'orde a Mallorca, examinador sinodal i consultor del Sant Ofici. El va cridar a Roma el seu íntim amic Agustín Pipia, mestre de l'orde (1721-1725), cap a on va partir el 27 d'octubre del 1722. Va ser nomenat teòleg Casanatense i agent de diverses causes que, en aquells temps, va tenir el convent de Mallorca. Breve Resumen... f. 209-210.

23 Com amb el conjunt documental utilitzat a l'apartat anterior, si no s'indica altrament, es continuaran accentuant en aquest document les paraules per facilitar-ne la comprensió; però per evitar les nombroses notes al peu, s'assenyalarà en el text la pàgina corresponent. 
D'aquest document romà, com dels anteriors, traspua que la qüestió de l'estigmatització s'havia de prendre amb molta cautela i que havia d'estar molt comprovada per tal que s'hi pronunciés el papa. Però no fa cap menció de les dones.

D’altra banda, a Roma es conserva també un text eloqüent de gran interès per a aquesta qüestió. Es troba en una carta del mestre català de l'orde, Tomàs Ripoll, al ja esmentat mestre Jacint Pujadas, del 19 de juliol del 1738, en la qual li diu: ${ }^{24}$ «Confieso que me cansan y cansan no poco essas historias con que cada día y en tantas partes nos molestan los [...] de nuestra doctrina y demás glorias de la orden, por lo que quisiera imprimir en los corazones de todos los frayles el que por lo menos por nuestra parte no demos motivo ya que tan desvelada está la crisis de aquellos para mortificarnos, mordemos y disputarnos todo. Ya veo que lo de la lámina de la beata Lucía ha sido una cosa innocente y que podía quietarse este señor inquisidor con lo que vuestra paternidad le dixo: vea si con lo que le dirá agora el Maestro Salas a quien he hecho ver en nuestro bullario los documentos y decretos pontificios que los suponen, le podrá quietar y con lo que puede assegurarle de que en esta corte y en otras infinitas partes no se disputa ni se ha disputado jamás este favor a la santa. Si todo esto no basta ya al maestro Raspeno (?), escrivan también a mi agente el Presentado Cavallero, si fuere menester dar algunos passos en la Suprema y veamos si esse señor acabara de conocer que no le aconsejan bien los que tan a menudo le hazen tomar empeños que no pueden subsistir. Pero prevengo que por ningún caso se envíe frayle alguno a la Corte, como la otra vez pues basta el que allí tenemos».

Febrer afirma que la Sagrada Congregació va sentir «in voce et in scriptis, resolvieron unanimiter los Eminentíssimos Padres Cardenales afirmative; es a saber, que havía sido lícito pintar la Beata Lucía con llagas sangrientas, patentes y visibles. Se expedió en Roma dicho Decreto el día 23 de enero del año $1740 \gg .^{25}$

A Roma es conserva també una interessant carta respecte a l'esmentat mestre de l'orde al presentat Pedro Mártir Alberti, frare del convent de Mallorca, datada el 6 de febrer del 1740, ${ }^{26}$ a qui li diu: «Ya gracias a Dios salimos y con mucha gloria de la causa de las llagas de nuestra Beata Lucía como verá Vuestra Paternidad Muy Reverenda por el decreto de la Sagrada Congregación que remitirá con esta el Padre Maestro Salas. Tuvimos favorables todos los señores excelentísimos cardenales que la componían, sin discrepar alguno. Me congratulo con Vuestra Paternidad y con toda esta mi amada comunidad, encargando, pero a todos, que no hagan demostraciones de la victoria que puedan ofender ni exasperar ni aún al más mínimo lego de los Padres Franciscanos nuestros hermanos, antes si les parece (aunque lo sabrán por los suyos) participarlo al Padre Provincial o [al Padre] Guardián, si aquel ya huviesse partido para el Capítulo General con toda cortesía y afabilidad, después de averlo participado con otra tanta civilidad al Señor Obispo, pidiéndole su permiso para defender las Conclusiones suspendidas por su Ilustrísima. Si consiente, no ay que decir sino a su lugar y tiempo defenderlas, sin hacer rencor ni gala de la causa ganada ni del chasco que todos llevan, quando su

24 Registro de cartas... f. 45v; donam les gràcies a Alejandro López Ribao op, qui ens l’ha facilitada.

25 Breve Resumen... f. 210-211.

26 Registro de cartas... f.124r-v; també ens l>ha proporcionada Alejandro López Ribao op. 
Ilustrísima repugnara -lo que no creo- avisar acá del reparo y del fundamento que tiene para no quitar la suspensión, pues que no dio otro que las llagas que no podían pintarse en la lámina o imagen de la beata Lucía. [124v] Espero que todo lo sabrá executar la prudencia y discreción de Vuestra Paternidad con el mayor acierto y que assí mismo lo persuadirá a sus súbditos para que no en púlpito no en escritos ni aún en conversaciones con seglares, den el más leve motivo de que nos jactamos de la victoria. Prediquen y escrivan el favor que Dios hizo a la beata Lucia y demás santas estigmatizadas, pero sin chasquidos, no cosa que pueda ofender a los que se han opuesto a ellas por mala intelligencia o por sobrado zelo de los de nuestro Padre San Francisco».

Sempre segons Febrer, «llegó a Mallorca el día 28 de febrero del mismo año. Se notificó el mismo día al Señor Obispo, y a los Padres de San Francisco. Y el día siguiente por la mañana cantó toda la Comunidad deste Real Convento [de Predicadores] con luzes en las manos, un solemne Te Deum ante la imagen de la Santa [?], y en acción de gracias por el éxito tan feliz de su Causa». ${ }^{27}$

Els dies 4 i 5 de juny següents es defensaren solemnement les Conclusions a l'església d'aquest convent, «con asistencia del Excellentíssimo Señor Comandante y Capitán General de este Reyno, de los Muy Illustres Señores Regidores de esta Ciudad, de los Muy Illustres Juezes y Regente de la Real Audiencia, de los Muy Illustres Canónigos y Cabildo de la Iglesia Catedral, de los Muy Illustres Señores Inquisidores, y un muy numeroso concurso de Cavalleros, Prelados de Religiones y Lectores dellas, y otras gravíssimas personas de todo estados [...] Dicho día 4 huvo solemníssimas Completas, y el día 5 y 6 siguientes solemne Fiesta, con música, y sermón a honor de la Beata Lucía y sus llagas». ${ }^{28}$

\section{4.- Conclusió}

Així doncs, com s'ha pogut observar, l'únic que prohibien les butlles de Sixte IV era que cap sant, santa, beat o beata es pintés o figurés amb llagues, com també que es prediqués sobre això, mentre no hi hagués una declaració del papa sobre el fet que el personatge en qüestió en tingués i les hagués rebudes del mateix Crist. La documentació utilitzada no deixa traslluir que existís desconfiança cap a la salut mental de les dones, pel fet que se les considerés proclius a aquest tipus de desvaris, com sí que pensaven alguns des de feia segles, en una expressió de la misogínia i el masclisme imperants. Tota aquesta controvèrsia també és, en el fons, una expressió més dels enfrontaments crònics entre franciscans, i més veladament jesuïtes, i els dominics a la Ciutat de Mallorca.

27 Breve Resumen... f. 211.

28 Breve Resumen... f. 211-212. 
Alfonso Esponera Cerdán \& Maria-Pilar Sastre Alzamora. Controvèrsia inquisitorial al segle XVIII entorn de la pintura d'una beata estigmatitzada

\section{Fonts}

Autos sobre haver sacado a luz una lamina de la Beata Lucia de Narni con llagas los PP. Dominicos, con dedicatoria a ella, en unas Conclusiones; y haver encendido una vela delante de otra, que está en la Capilla de los Reyes, después de haverseles mandado suspender las Conclusiones, conservat a ANA Inquisición 446, n. 9.

Breve resumen o recuerdo histórico de las grandezas y excelencias del Real Convento de santo Domingo de Palmay de algunos de sus ilustres hijos. Ordenado por fr. Tomás Febrer y escrito por fr. Dalmacio Moll. Año 1754. Vol. III. MSL/ 181, conservat a l'Arxiu Diocesà de Mallorca.

Discurso juridico sobre la suspencion de Conclusiones que bizo el Señor Obispo en el Convento de Santo Domingo de la ciudad de Palma por estar pintada en ellas la Beata Lucia de Narni con llagas, y referirse que las tuvo en la dedicatoria, conservat a AGOP. Sèrie XIII. 21.100 (Epistulae variaque documenta, 1571-1777).

Registro de cartas de Ripoll de 1738-1742 (no minutas), conservat a AGOP IV 209f.

\section{Bibliografia}

Benavente Eyriey, I. (2008) Santasy Beatas de la Orden de Predicadores (1207-2007), Torrente, Federación de la Inmaculada Concepción de Monjas Dominicas, pp. 200-207.

Brugnola, G. (1989) Lucía Brocadelli e il suo tempo. Narni.

Campaner, A. (1881 [2007]) Cronicón Mayoricense, Ed. «Sa Nostra», Mallorca.

Esponera Cerdán, A. (2004) «Los dominicos, Sor Ania y la Causa lulista en Mallorca en la segunda mitad del siglo XVIII», Escritos del Vedat XXXIV, pp. 245-274.

Granello, T.M. (1879) La B. Luvia da Narni. Ferrara.

Massot i Muntaner, J. (1961) «Fray Benito Pañelles, obispo de Mallorca», Analecta Sacra Tarraconensia, XXXIV, pp. 204-205 nota 24.

Montero, A. (2016) «Beata Lucía de Narni», a Martínez Puche, J.A. (dir.) El Año Dominicano: 12261229, Madrid, Edibesa.

Pérez Martínez, L. (1966) «Intervención de Benedicto XIV en la Causa Luliana», Anthologica Annua XIV, pp. 194-199.

- (1986) «Datos sobre el antilulismo del dominico fray Martín Serra (+1715)», a Homenaje a D. Jesús García Pastor. Bibliotecario, Direcció General de Cultura, Palma, pp. 63-77.

Reichert (ed.),(1904) Acta Capitulorum Generalium Ordinis Praedicatorum IX, Romae, Curia Generalicia, pp. 106-107.

Sanxo, P.A. (1930-1931) «Sobre representar estigmatitzada a Santa Catarina de Sena (1472)», Bolletí de la Socitat Arqueologica Lul tliana XXIII, p. 436. 